\title{
ESCOLA SEM PARTIDO: A LEGITIMAÇÃO DE UM RETROCESSO
}

\section{SCHOOL WITHOUT PARTY: THE LEGITIMACY OF A RETROGRADE STEP}

\author{
Tiago Florentino GONÇALVES ${ }^{1 *}$, Jaqueline Cristina SILVA ${ }^{2}$, Danilo Henrique NUNES ${ }^{3}$ \\ ${ }^{1 \text { e } 2}$ Graduando em Bacharelado em Direito no Centro Universitário da Fundação Educacional de Barretos - \\ Unifeb, Av. Professor Roberto Frade Monte 389, Aeroporto, CEP 14283-078, Barretos-SP. \\ 3 Advogado e professor do curso de Bacharelado em Direito do Centro Universitário da Fundação \\ Educacional de Barretos - Unifeb, Av. Professor Roberto Frade Monte 389, Aeroporto, CEP 14283-078, \\ Barretos-SP.
}

\begin{abstract}
RESUMO
O trabalho visa analisar a partir de um entendimento da orientação das legislações educacionais, e sob a luz das doutrinas construídas na área, se a Educação Básica, enquanto direito social pelo qual o Estado deve agir para criar uma igualdade entre os indivíduos promovendo a dignidade humana e o bem-estar social, sendo fundamental para a transformação de uma sociedade mais justa, tem sido afetada positiva ou negativamente por possíveis alterações na Lei $n^{\circ}$ 9.394/1996, que estabelece as Diretrizes e Bases da Educação, pela Medida Provisória n ${ }^{\circ} 746 / 2016$ e pelos Projetos de Lei no 867/2015 e nº 1.411/2015, assim como pelo Projeto de Lei do Senado $n^{\circ}$ 193/2016, além da mudança dos investimentos públicos, incluindo na área da educação, em razão da Proposta de Emenda à Constituição nº 241/2016. Legalmente, a educação tem por finalidade a promoção da igualdade entre os indivíduos, criando uma sociedade livre, justa e igualitária, sendo o pilar da construção, até este momento, preocupada em formar o cidadão para que tenha uma leitura crítica do mundo atuando de forma crítica na transformação da sociedade. Em análise dos três projetos, foi possível perceber aspectos relevantes se mostram um retrocesso à educação, havendo resquícios até de inconstitucionalidade ao contrariar os objetivos da República Federativa do Brasil. Ainda, as três juntas, se aprovadas, podem estabelecer uma crise ainda mais grave, atrasando o país por décadas.
\end{abstract}

Palavras-chave: Educação, Transformação e Retrocesso.

\begin{abstract}
The work aims to analyze from an understanding of the orientation of educational legislation, as well as in light of the doctrines that have been built in the area if Basic Education, as a social right by which the state must act to create equality between individuals by promoting Human dignity and the social welfare, being fundamental for the transformation of a more just society, has been positively or negatively affected by possible amendments to Law 9,394 / 1996, which establishes the educational guidelines and bases: Provisional Measure No. 746/2016; as well as the "No Party School" of Bill Project 867/2015 and 1411/2015 and of Senate Bill Project 193/2016; so as the change of public investments, including in the area of education by the Proposed Amendment to the Constitution 241/2016. Legally, education aims to promote equality between individuals by creating a free, fair and equal society; education being pillar of the built up to this moment concerned with training the citizen for a critical reading of the world, so that
\end{abstract}

\footnotetext{
*Autor para Correspondência: Tiago Florentino Gonçalves - Endereço: Rua L-12, 329, Los Angeles, Barretos-SP-CEP 14787-076 - E-mail: tiagoflorentinogoncalves@gmail.com - Telefone: (14) 981309628 Recebido em: 07/07/2017
}

Aceito para publicação em: 09/10/2017

https://doi.org/10.4322/1980-0029.082017 
it can act critically in the transformation of society. In the analysis of the three projects it was possible to perceive that even with certain relevant aspects they show a regression with the education, with remnants of even unconstitutionality against the objectives of the Federative Republic of Brazil. Still, the three boards, if approved, could establish an even more serious crisis, delaying the country for decades.

Keywords: Education, Transformation and Retrograde Step.

\section{INTRODUÇÃO}

No Brasil, desde a época do Império, houve uma preocupação com a educação. Na constituição promulgada por Dom Pedro I em 1824, havia dois artigos que faziam referência a educação, dos quais um deles acerca da gratuidade da educação primária. Apesar de não se efetivar na prática, foi um dos primeiros países a garantir em seu texto constitucional tal serviço de forma gratuita (VIERA, 2007). Houve ainda a Lei de 15 de outubro de 1827, que mandava criar escolas de primeiras letras em todas as cidades, para ensinar a leitura, a escrita, as quatro operações aritméticas, a geometria, bem como a moral cristã, com base nos textos da Constituição do Império e História do Brasil (BRASIL, 1827), mas não tendo sido executada na prática.

Porém, é perceptível com isso que, em quase dois séculos, busca se incorporar a educação enquanto um preceito constitucional necessário para o desenvolvimento do país. Assim, em cada momento em que as constituições foram promulgadas, há aspectos diferentes da educação, ora mais liberal, ora mais conservadora, ora reformista, seguindo de acordo com os interesses, as épocas e os anseios sociais, avaliados no Legislativo, mostrando-se por vezes contraditórios (VIERA, 2007).

Já na atual Carta Magna, a Constituição da República Federativa do Brasil de 1988 (BRASIL, 1988), feita logo após a época de recesso de direitos na ditadura, traz, no art. $6^{\circ}$, a educação enquanto um direito social, ou seja, há a necessidade de atuação do Estado para a criação de um estado de direito para todos os cidadãos com bem-estar social, igualando os direitos fundamentais.

Os direitos sociais são aqueles que têm por objetivo garantir aos indivíduos condições materiais tidas como imprescindíveis para o pleno gozo dos seus direitos, por isso tendem a exigir do Estado uma intervenção na ordem social que assegure os critérios de justiça distributiva, assim diferentemente dos direitos a liberdade, se realizam por meio de atuação estatal com a finalidade de diminuir as desigualdades sociais, por isso tendem a possuir um custo excessivamente alto e a se realizar em longo prazo (PESSOA, 2011).

Para Pessoa (2011), a educação vai além de um direito social, para ele, é um direito fundamental, pois é só tendo sido educado que uma pessoa consegue exercer seus direitos civil, político, econômico ou social. Dessa forma, para a existência das pessoas de uma forma não sub-humana, esse direito se torna essencial para a manutenção do princípio da dignidade humana.

Em uma rápida visualização, pode-se vislumbrar a importância da educação, sendo assegurada constitucionalmente para uma transformação social e equiparação de direitos, fundamental para a atuação dos sujeitos enquanto cidadãos na busca dos seus direitos e para a realização de seus deveres com o objetivo de construir uma sociedade mais justa e igualitária.

No art. 205 da nossa Carta Magna, é definido:

[...] a educação, direito de todos e dever do Estado e da família, será promovida e incentivada com a colaboração da sociedade, visando ao pleno desenvolvimento da pessoa, seu preparo para o exercício da cidadania e sua qualificação para o trabalho (BRASIL, 1988).

Sendo assim, tem-se um apontamento que reforça a educação enquanto um direito social, consequentemente, um dever do Estado; entretanto, pelo texto da lei, também é percebido como um dever de todas as pessoas. Essa última parte é algo que tem sido muito discutido, pois há uma sobrecarga das instituições devido à falta de participação da família e da sociedade no processo educacional. E, ao estabelecer "o pleno desenvolvimento da pessoa", há a criação de um parâmetro de direito subjetivo que, relacionado ao todo, conecta um direito objetivo impositivo de dever com um subjetivo (SARLET; MARINONI; MITIDIERO, 2013). 
Ainda é possível dividir o objetivo da educação em três aspectos, conforme aponta a lei: o desenvolvimento pleno da pessoa; a formação para exercício da cidadania; e a qualificação do trabalho. De uma forma simples, o trabalho se relaciona às formações técnicas necessárias para que as pessoas exerçam uma função social, auxiliando no desenvolvimento da nação. A formação para cidadania se refere à atuação de todo indivíduo enquanto cidadão, ou seja, cumprindo com seus deveres e buscando seus direitos para a transformação de uma sociedade mais justa. E, por último, o desenvolvimento pleno da pessoa reflete uma preocupação com a complexidade do ser, considerando os aspectos racionais, emocionais, sociais, entre outros.

Na Lei de Diretrizes e Bases da Educação Nacional LDB, Lei no 9.394 (BRASIL, 1996), visando à orientação comum, tem-se a definição de alguns dos objetivos da educação para possibilitar a humanização e o desenvolvimento dos indivíduos em suas dimensões cognitiva, afetiva, cultural, social, dialógica e crítica, para que sejam atores na busca de uma sociedade mais justa.

Ainda, são estabelecidas, tanto na Constituição (BRASIL, 1988) quanto na LDB (BRASIL, 1996), algumas diretrizes para a fomentação da educação. $\mathrm{Na}$ Constituição, há alguns princípios dispostos no art. 206, que são reforçados pela LDB:

igualdade de condições para o acesso e permanência na escola; liberdade de aprender, ensinar, pesquisar e divulgar o pensamento, a arte e o saber; pluralismo de idéias e de concepções pedagógicas, e coexistência de instituições públicas e privadas de ensino; gestão democrática do ensino público, na forma da lei; garantia de padrão de qualidade.

Por isso, pode-se perceber que a escola tende a ser um espaço para todos, onde seja possível trabalhar os diversos conhecimentos inerentes à complexidade do homem, favorecendo uma gestão em que todos tenham a participação da decisão, de uma forma democrática e com qualidade.

Também se formaliza na LDB (BRASIL, 1996) a garantia de acesso de crianças de 4 a 17 anos de idade a uma educação básica gratuita, fornecida pelo Estado, sendo inclusiva e que considere as necessidades e a disponibilidade para a permanência delas, observando o "acesso aos níveis mais elevados do ensino, da pesquisa e da criação artística, segundo a capacidade de cada um" (BRASIL, 1996). Com isso, vê-se que há uma intensa preocupação com o tipo de educação que será realizado. Ainda, a LDB estabelece a necessidade de um Plano Nacional de Educação que passe, a partir da Emenda Constitucional n ${ }^{\circ}$ 59/2009, a ter periodicidade decenal, estabelecendo as atuações do governo durante determinado prazo, respeitando as necessidades da educação de forma atual, incluindo questões de propositura internacional.

A Lei $n^{\circ} 13.005 / 2014$ é que estabelece o atual Plano Nacional de Educação com vigência de 10 anos. Em seu art. $2^{\circ}$, são traçadas as diretrizes que todos os planos plurianuais devem respeitar, entre outras:

erradicação do analfabetismo; superação das desigualdades educacionais, com ênfase na promoção da cidadania e na erradicação de todas as formas de discriminação; melhoria da qualidade da educação; formação para o trabalho e para a cidadania, com ênfase nos valores morais e éticos em que se fundamenta a sociedade; promoção humanística, científica, cultural e tecnológica do País; estabelecimento de meta de aplicação de recursos públicos em educação como proporção do Produto Interno Bruto - PIB, que assegure atendimento às necessidades de expansão, com padrão de qualidade e equidade; promoção dos princípios do respeito aos direitos humanos, à diversidade e à sustentabilidade socioambiental (BRASIL, 2014a).

Não é difícil notar a importância dada pelo conjunto dessas leis que determina a obrigatoriedade de educação de qualidade, bem como seus princípios e suas diretrizes.

Também no PNE, em seu art. $2^{\circ}$, há diretrizes como:

superação das desigualdades educacionais, com ênfase na promoção da cidadania e na erradicação de todas as formas de discriminação; melhoria da qualidade da educação; promoção do princípio da gestão democrática da educação pública; promoção humanística, científica, cultural e tecnológica do País; promoção dos princípios do respeito aos direitos humanos, à diversidade e à sustentabilidade socioambiental (BRASIL, 2014a).

É visível a preocupação com a universalização da educação para a cidadania, com a complexidade do ser, incluindo uma educação que respeite o outro, a sociedade e o meio ambiente, tendo com uma das metas a sustentabilidade.

O documento do Plano Nacional de Educação foi elaborado para ser respeitado em todo o país, e, em todo planejamento anual, todas as escolas devem estar em conformidade com essas orientações. 
Foram publicadas as 20 metas para a educação no período de 2014-2024 (BRASIL, 2014b, c), nas quais se encontram alguns tópicos com o propósito de universalizar a educação tanto nos ensinos infantil, fundamental e médio de forma inclusiva, elevar os níveis de educação e alfabetização, valorizar e elevar a formação dos professores. O texto ainda coloca outros tópicos, como:

...fomentar a qualidade da educação básica em todas as etapas e modalidades, com melhoria do fluxo escolar e da aprendizagem;(...) ampliar o investimento público em educação pública de forma a atingir, no mínimo, o patamar de 7\% (sete por cento) do Produto Interno Bruto (PIB) do País no 5o (quinto) ano de vigência desta Lei e, no mínimo, o equivalente a $10 \%$ (dez por cento) do PIB ao final do decênio (BRASIL, 2014b).

Ainda, o Plano Nacional de Educação estabelece como objetivos:

Elaborar um plano de educação no Brasil, hoje, implica assumir compromissos com o esforço contínuo de eliminação de desigualdades que são históricas no País. Portanto, as metas são orientadas para enfrentar as barreiras para o acesso e a permanência; as desigualdades educacionais em cada território com foco nas especificidades de sua população; a formação para o trabalho, identificando as potencialidades das dinâmicas locais; e o exercício da cidadania. A elaboração de um plano de educação não pode prescindir de incorporar os princípios do respeito aos direitos humanos, à sustentabilidade socioambiental, à valorização da diversidade e da inclusão e à valorização dos profissionais que atuam na educação de milhares de pessoas todos os dias (BRASIL, 2014b).

De tudo isso, pode-se perceber a preocupação com uma educação de qualidade e universal desde o Império, evoluindo até a Constituição de 1988, nas busca pelo desenvolvimento pleno da pessoa, considerando a complexidade do ser humano, além de ser fundamental para a formação para a cidadania, para que o sujeito possa ser ator crítico de uma transformação, buscando seus direitos e exercendo seus deveres, incluindo o trabalho, de forma consciente.

Ainda é preciso considerar a questão do processo educativo como um desenvolvimento separado, realizado pelos profissionais da área que constroem a educação no seu dia a dia.

\section{MATERIAIS E MÉTODOS}

Este foi um trabalho de revisão literária, no qual, a partir do estudo de diversas leis (BRASIL, 1827, 1988, 1996, 2014a, b, c), de doutrinas relacionadas à educação e às legislações (FREIRE, 1970, 1979; BARROS; MENDONÇA, 1997; MARIN, 2002; BRANDÃO, 2007; VIERA, 2007; PESSOA, 2011; SARLET; MARINONI; MITIDIERO, 2013) e também de alguns periódicos e documentos com análises e pareceres sobre os projetos (ABDALLA; DRECHSEL, 2016; BRASIL, 2016b; NAGIB, 2016; OTTO, 2016; TOKARNIA, 2016; SAMPAIO, 2016), tentou-se compreender melhor os objetivos e as repercussões que os Projetos de Lei (BRASIL, 2015a, b, 2016d), a Medida Provisória (BRASIL, 2016a) e a Proposta de Emenda à Constituição (BRASIL, 2016c) poderiam acarretar no desenvolvimento nacional, mais relacionado às questões educacionais. Por fim, foram feitas considerações por meio dedutivo e reflexivo de tudo o que foi pesquisado para buscar compreender se tais adições ao ordenamento jurídico, de alguma forma, caracteriza-se como um contraponto ou não ao que se tem construído na educação e a orientado, ou seja, se pode ser considerado um retrocesso ou um avanço ao processo educacional do país.

\section{DISCUSSÃO}

Existem diversos autores que discutem o tema, pois muito se diz sobre o que é educação, qual é a sua finalidade e como realizá-la. De uma forma um pouco mais rasa, busca-se aqui abordar esses tópicos para um entendimento inicial, requerido para o entendimento deste trabalho.

A educação, de uma forma simples, é só uma ferramenta pela qual se dá o processo de transmissão e construção de conhecimentos entre gerações para o desenvolvimento da sociedade. Segundo Brandão (2007), a educação não é uma exclusividade das instituições escolares da sociedade moderna; antes, ocorre em todos os grupamentos sociais nos quais o homem transmite costumes, tradições e crenças. Ainda, define que hoje há esses espaços orientados por metodologias pedagógicas onde ocorre a educação formal.

Primeiro que tudo, a educação não é uma propriedade individual, mas pertence por essência a comunidade. O caráter da comunidade imprime-se em cada um dos seus membros e é no homem... muito mais que nos animais, fonte de toda a ação e de todo o 
comportamento. Em nenhuma parte o influxo da comunidade nos seus membros tem maior força que no esforço constante de educar, em conformidade com o seu próprio sentir, cada nova geração (JAEGER, 2001 apud BRANDÃO, 2007).

Brandão (2007) discute também a ideia da finalidade da educação. Para ele, é comum a divisão de saberes da educação, com a ocorrência, às vezes, de um desvio de finalidade, ou seja, para alguns grupos há um tipo de saber, enquanto para outros, não é o mesmo. Isso causa uma diferença na igualdade da educação, tornando-a como uma possível ferramenta de controle, em razão de um desvio no seu fim. Assim, alguns grupos com uma educação diferenciada legitimam o controle do poder, causando uma desigualdade social. Por isso, as finalidades que a educação tem enquanto processo deve ser muito bem observada.

O autor define também a diferença na Grécia Antiga da educação técnica realizada para os escravos, a fim de dar suporte às suas funções, e o saber teórico realizado com os nobres. Essa divisão, segundo ele, persiste até hoje como uma forma de controle social realizado por um grupo de indivíduos, em que a educação popular é mais técnica, enquanto somente uma minoria tem uma formação realmente crítica.

Freire (1979) disserta sobre a educação como uma forma de mudança, com o objetivo de aperfeiçoar o homem e, com isso, causar mudança social. Para uma transformação efetiva, não deve haver uma educação alienante, mas sim uma educação crítica, fugindo da ingenuidade e da imitação; o homem deve entender sua realidade para conseguir construí-la de uma forma mais justa, necessária a uma "democratização fundamental", ou seja, um aumento da participação da população na construção histórica da sociedade, deixando de ser meros espectadores para ser atores sociais. Por isso, é fundamental uma educação reflexiva crítica na qual os sujeitos tenham uma base de pensamento para repensar a realidade e, assim, atuar de forma adequada nas transformações sociais.

Já em sua outra obra, Freire (1970) coloca em destaque a educação como um processo de aculturamento para facilitar a opressão. Assim, a educação não crítica tem por finalidade manter o poder, favorecendo o opressor. Nessa oposição entre oprimido-opressor é que ele discute a ideia de uma educação em que haja a liberdade de um pensamento crítico, na qual os sujeitos possam fazer uma leitura da realidade e, dessa forma, atuar em uma transformação social. Entretanto, para isso, é necessário que a educação não seja somente técnica, mas que dê base para que os indivíduos que são oprimidos na sociedade tenham a capacidade, não de se tornarem opressores, mas de fazer uma leitura dialógica crítica do mundo e de transformar a sociedade, acabando com essa dicotomia e construindo uma sociedade mais justa e igualitária.

Dessas noções básicas de educação, percebe-se a educação enquanto um processo histórico, o qual deve ser analisado com muito cuidado, por ser uma ferramenta que pode tender a uma dominação, dependendo da orientação que tiver. A educação, portanto, pode ser tanto um instrumento de controle como um instrumento de libertação. A única diferença entre esses dois pontos é uma educação técnica que não se preocupe com a liberdade de pensamento crítico dos sujeitos, em oposição a outra que seja fundamental, que possibilite uma leitura crítica da realidade e não seja pronta ou acabada, mas esteja em constante transformação para se aperfeiçoar e, por isso, ser dialética, como forma de causar uma mudança na sociedade pelos próprios sujeitos, os quais deixem de ser instrumentos e passem a ser construtores críticos de uma transformação social, estruturando uma sociedade para todos na qual a dignidade humana e os direitos fundamentais sejam universalizados.

Assim, a educação é uma importante ferramenta para a efetivação de uma sociedade mais justa, se feita de forma adequada, ou então para a manutenção de um estado de desigualdades, no qual as pessoas não consigam atuar para a mudança social; por isso, é de fundamental importância que a educação seja realizada de maneira apropriada. E, de tão importante que é, vem sendo objeto das constituições desde o Império. Na atualidade, há projetos polêmicos que fazem algum tipo de regulamentação legal da educação, os quais serão analisados agora.

\section{RESULTADO}

Este trabalho visa compreender um pouco melhor três formas de legislação que estão em processo de promulgação no Congresso Nacional que versam sobre a educação. O objetivo aqui é, sob à luz do que já foi exposto, compreender se tais legislações podem ser caracterizadas como um avanço ou um retrocesso ao processo educacional 
que visa a um desenvolvimento do país, respeitando a Carta Magna.

\section{Os Projetos de Lei $n^{o} 867 / 2015$ e $n^{o}$ 1.411/2015 e do Projeto de Lei do Senado $n^{\circ} 193 / 2016$}

O PL no 867/2015 e o PLS nº 193/2016 são os mesmos projetos, entretanto um tramita na Câmara dos Deputados, e outro, no Senado, havendo pouca diferença. Ambos versam sobre o "Escola Sem Partido", como ficaram conhecidos, que modificam a Lei de Diretrizes e Bases da Educação Nacional. No geral, a ideia é que haja uma neutralidade ideológica dentro das escolas, não havendo uma doutrinação política, moral e ideológica, com o acréscimo, no texto que está no Senado, da vedação de uma educação de gênero. A justificativa apresentada no projeto é de que:

É fato notório que professores e autores de materiais didáticos vêm se utilizando de suas aulas e de suas obras para tentar obter a adesão dos estudantes à determinadas correntes políticas e ideológicas para fazer com que eles adotem padrões de julgamento e de conduta moral - especialmente moral sexual - incompatíveis com os que lhes são ensinados por seus pais ou responsáveis (BRASIL, 2016d).

Vê-se que a grande preocupação dos dois projetos é o possível aproveitamento realizado pelos docentes para doutrinação dos alunos, já que estes são considerados sujeitos frágeis, a parte mais fraca da relação, passíveis de uma fácil dogmação. $\mathrm{O}$ texto ainda mostra que essa é uma realidade usual, sendo necessária uma intervenção urgente para que não ocorra mais.

Nesse sentido, a PL n ${ }^{\circ} 1.411 / 2015$ tipifica o crime de assédio ideológico como toda prática que

adotar determinado posicionamento político, partidário, ideológico ou qualquer tipo de constrangimento causado por outrem ao aluno por adotar posicionamento diverso do seu, independente de quem seja o agente (BRASIL, 2015a).

Enquanto justificativa para esse projeto que torna crime as possíveis ações do professor e outros funcionários envolvidos com a educação dentro da escola, tem-se:

A forma mais eficiente do totalitarismo para dominar uma Nação é fazer a cabeça de suas crianças e jovens. Quem almeja o poder total, o assalto à Democracia, precisa doutrinar por dentro da sociedade, estabelecer a hegemonia política e cultural, infiltrar-se nos aparelhos ideológicos e ser a voz do partido em todas as instituições (BRASIL, 2015a).

O texto da lei ainda traz como justificativa o fato de que um partido, em períodos de guerra, adota o aumento de recursos nas áreas da comunicação, da educação, da cultura e do esporte, considerando que, para haver mudanças, é necessário mexer no cerne social, criando raízes mais profundas dessa nova cultura (BRASIL, 2015b). Tal texto de justificativa não é neutro, e sim retirado especificamente de uma carta do Partido dos Trabalhadores.

Hyago Souza Otto (2016), contrariando esse movimento, ao apontá-lo como não eficaz para uma boa formação e inconstitucional por lesar a liberdade de expressão do professor, afirma que não existe imparcialidade na educação, pois não há pessoa sem orientação política.

O professor Fabiano Godinho Faria mostra uma preocupação pelo fato de o projeto de lei reforçar uma postura ideológica conservadora surgida no período pré-1964, antes da instauração da ditadura militar no Brasil. Professor Faria avalia que:

É algo típico do período da Guerra Fria. O objetivo explícito é perseguir, demitir e até prender os docentes que defendam uma visão de mundo contrária ao status quo. Colocar a educação a serviço da manutenção de uma visão de mundo dessas é um retrocesso, porque afronta avanços que tivemos nas últimas décadas. Nós chegamos ao ponto de tratar o racismo como crime, de aceitar a união homoafetiva, e o projeto tenta criminalizar esse tipo de discussão. É uma ode ao atraso (SAMPAIO, 2016).

Do outro lado, em defesa do projeto, Nagib (2016) reforça a ideia de que o "Escola Sem Partido" é uma forma de proteger o aluno que é a parte mais fraca na relação ensino-aprendizagem em sala de aula. Assim, por ser uma audiência cativa, o professor pode catequizar o aluno para agir não de forma crítica, mas sim em conformidade com suas ideias. Ainda, nesse sentido, tenta mostrar que a liberdade de expressão usada como forma de classificar o projeto como inconstitucional é diferente da liberdade de ensinar, a qual deve seguir certos parâmetros e ser neutra, o que é o objetivo do projeto. Como defesa, aponta que o que não pode é:

...desrespeitar a liberdade de consciência e de crença e a liberdade de aprender dos alunos (art. $5^{\circ}$, VI e VIII; e art. 206, II, da CF), o princípio constitucional da neutralidade política, ideológica e religiosa do Estado (art. $1^{\circ}$, V; $5^{\circ}$, caput; 14, caput; 17, caput; 19, 34, VII, 'a', e 37, caput, da CF), o pluralismo 
de ideias (art. 206, III, da CF) e o direito dos pais dos alunos sobre a educação religiosa e moral dos seus filhos (Convenção Americana sobre Direitos Humanos, artigo12, IV) (NAGIB, 2016).

Em uma nota técnica, a Procuradora Federal dos Direitos do Cidadão, Deborah Duprat, faz um parecer sobre os projetos do "Escola Sem Partido", mostrando que ele confunde a educação escolar com a educação familiar, impede o pluralismo de ideias, nega a liberdade de cátedra e contraria o princípio de laicidade do Estado. Ainda coloca que o projeto está na contramão dos objetivos fundamentais da República em construir uma sociedade livre, justa e solidária:

O que se revela, portanto, no PL e no seu documento inspirador é o inconformismo com a vitória das diversas lutas emancipatórias no processo constituinte; com a formatação de uma sociedade que tem que estar aberta a múltiplas e diferentes visões de mundo; com o fato de a escola ser um lugar estratégico para a emancipação política e para o fim das ideologias sexistas - que condenam a mulher a uma posição naturalmente inferior, racistas - que representam os não- brancos como os selvagens perpétuos, religiosas - que apresentam o mundo como a criação dos deuses, e de tantas outras que pretendem fulminar as versões contrastantes das verdades que pregam (BRASIL, 2016b).

\section{A Medida Provisória no 746/2016}

Institui a Política de Fomento à Implementação de Escolas de Ensino Médio em Tempo Integral, altera a Lei $n^{\circ}$ 9.394, de 20 de dezembro de 1996 , que estabelece as diretrizes e bases da educação nacional, e a Lei $\mathrm{n}^{\circ} 11.494$ de 20 de junho 2007, que regulamenta o Fundo de Manutenção e Desenvolvimento da Educação Básica e de Valorização dos Profissionais da Educação, e dá outras providências (BRASIL, 2016a).

Essa Medida Provisória, inicialmente, institui o aumento da carga horária mínima anual nas escolas para 1.400 horas, a qual, atualmente, é de 800 , tendo que ser implementada de forma progressiva, sendo obrigatório os estudos de Língua Portuguesa, Matemática e conhecimento do mundo físico e natural e da realidade social e política, especialmente do Brasil. Inclui o ensino de língua estrangeira a partir do sexto ano e dos temas transversais, os quais devem estar ser incluídos na Base Nacional Curricular Comum.

Define ainda para o Ensino Médio os temas de Linguagens, Matemática, Ciências da Natureza e formação técnica e profissional. Ainda coloca que deve haver uma preocupação com a formação integral dos alunos, trabalhando os projetos de vida e a formação de aspectos cognitivos e socioemocionais.

A Medida Provisória retira a obrigatoriedade do ensino de Artes e da Educação Física do Ensino Médio, bem como as disciplinas de Filosofia, História, Sociologia, Geografia e outras, sendo consideradas obrigatória durante os três anos somente as disciplinas de Língua Portuguesa e Matemática.

Também a lei determina que o financiamento deve vir do Fundo Nacional para o Desenvolvimento da Educação, sujeito à aprovação do Ministério da Educação, sendo acrescido de acordo com o número da matrícula de cada escola. Outra questão abordada é a implementação, que deve ocorrer, no geral, em dois anos.

Em relação à crítica, tem-se que perceber que a Medida Provisória está sendo imposta sem uma discussão prévia para a sua composição de forma adequada, que deveria contar com todo o corpo que faz parte das instituições públicas de educação, em especial os professores. As maiores críticas estão relacionadas à falta de formação do docente para tal processo, bem como à falta de estrutura e verbas necessárias para a transformação, como apontado por Tokarnia (2016). Ainda, tal autora mostra algumas palavras da secretária-geral, Marta Vinelli, da Confederação Nacional dos Trabalhadores em Educação, que tem se posicionado contra a Medida Provisória: "Estamos perplexos ao receber uma MP para tratar desse tema. E a perplexidade é tanto quanto ao método de apresentação quanto no conteúdo, por isso as pessoas lá atrás estão muito inquietas" (TOKARNIA, 2016).

A Medida Provisória tem sido tema controverso em diversos âmbitos, tanto que existem duas Ações Diretas de Inconstitucionalidade distribuídas no Supremo Tribunal Federal: uma delas, a ADI 5.604, foi ajuizada pela Confederação Nacional dos Trabalhadores em Educação, e a outra, a ADI 5.599, pelo Partido Socialismo e Liberdade. As duas ações serão julgadas conjuntamente. A argumentação usada para fundamentar a primeira está no caput do art. 62 da Constituição Federal, a qual prevê que as hipóteses da Medida Provisória são questões de relevância e urgência; com isso, não sendo um caso de urgência, ele não deveria ser realizado por meio de uma Medida Provisória. 
Ainda há a sustentação de que há vícios materiais, como violações dos arts. 205 e 206 , que tratam das diretrizes constitucionais sobre a educação.

O coordenador geral da Campanha Nacional pelo Direito à Educação, Daniel Cara, apontou, a partir de pesquisas, que alguns dos conteúdos retirados pela MP são de interesse dos alunos, como Educação Física e Artes. Ainda ressalta que não há recursos para instituir o ensino integral. Do outro lado, a secretária executiva do Ministério da Educação, Maria Helena Guimarães, mostra que a MP não exclui as disciplinas, mas deixa essa regulamentação para a Base Nacional Comum Curricular, a qual será aplicada em 2018, com a educação integral sendo uma necessidade para solucionar os problemas da educação no país (TOKARNIA, 2016).

Ricardo Falzetta, gerente de conteúdo do movimento Todos pela Educação, acredita que a Medida Provisória não está de acordo com os processos educacionais, os quais precisam ser dialogados com público envolvido, criticando a forma de aplicação sem o prévio debate de forma adequada. Também um professor da Universidade de São Paulo, doutor em educação, questiona a MP e vê nela uma forma abrupta de o governo induzir uma mudança no Ensino Médio (ABDALLA; DRECHSEL, 2016).

Existem, entretanto, opiniões contrárias, como a professora visitante de Harvard e ex-diretora de educação do Banco Mundial, Claudia Constin, que acredita que o modelo que se tem é muito engessado, com um conteúdo muito amplo para ser abordado em um número de horas tão pequeno, mas que seria possível, com mais tempo, trazer maior significância do conteúdo para a realidade dos alunos (ABDALLA; DRECHSEL, 2016).

No geral, realmente há uma necessidade no país de se ampliar o tempo destinado à educação. A criação de escolas integrais realmente parece ser uma boa saída para se adequar aos diversos tipos de conteúdo com a profundidade e a contextualização que deve ser dada. Entretanto, criar uma lei por meio de Medida Provisória, não levando ao público a discussão, parece errado, pois não considera uma construção coletiva e crítica da educação, podendo sofrer um direcionamento. Além disso, a obrigatoriedade de somente disciplinas de Língua Portuguesa e Matemática durante os anos do ensino médio parece reduzir a possibilidade de discussão e abrangência de conteúdos em outras disciplinas, como Filosofia, Sociologia, História e Geografia, matérias que levam à formação mais crítica dos alunos sobre a realidade.

Contudo, forçar uma legislação por meio de uma Medida Provisória sem a discussão parece um direcionamento político-ideológico e, mesmo quando cria uma educação integral, reduz a obrigatoriedade de disciplinas que têm sido colocadas historicamente nos currículos para formar de maneira crítica os alunos.

\section{A Proposta de Emenda à Constituição n $^{\circ}$ 241/2016}

Essa proposta vista alterar o regime financeiro por 20 exercícios, ou seja, por 20 anos, podendo ser alterada depois dos 10 primeiros. Inicialmente, coloca um limite às despesas primárias ${ }^{1}$ totais

do Poder Executivo, do Poder Judiciário, do Poder Legislativo, inclusive o Tribunal de Contas da União, do Ministério Público da União e da Defensoria Pública da União (BRASIL, 2016c).

O mecanismo para redução dos gastos altera legalmente os textos constitucionais referentes à autonomia que cada uma dessas partes tem de alterar livremente o orçamento, congelando-o basicamente com valor igual ao de 2016, corrigido pela variação do Índice Nacional de Preços ao Consumidor Amplo IPCA. A lei não altera os repasses da União aos governos e possibilita a tomada de créditos extraordinários, o aumento de despesas com estatais não dependentes e as despesas com eleição.

Também, a proposta altera a proibição da União e dos governos de repassar o percentual mínimo previsto na Constituição, ou seja, para manter o orçamento, é possível reduzir o repasse para os serviços de saúde e educação abaixo do mínimo previsto pela constituição, congelando o investimento da mesma forma já citada.

Em caso do descumprimento de tal medida, serão vedados a criação de cargos, o aumento de salários ou gastos, a realização de concursos públicos e outras ações que possam encarecer os serviços.

\footnotetext{
${ }^{1}$ Conjunto de gastos que o governo tem para manter os serviços públicos, tirando os custos financeiros decorrentes dos juros, o que leva a um comparativo entre o dinheiro arrecadado e o dinheiro gasto para executar as políticas públicas.
} 
No geral, essa medida congela os gastos por 20 anos, algo que é necessário pela notada crise econômica pela qual se passa; entretanto, a medida inclui os gastos com saúde e educação, possibilitando que exista um investimento menor nestes últimos que o previsto na Constituição sem a Emenda.

O tema é tão controverso que houve até a impetração de um Mandado de Segurança, MS $n^{\circ} 3.448$, realizado por alguns deputados, dizendo que a restrição era competência do Congresso Nacional, o qual deveria versar sobre orçamento da União, podendo ferir suas atribuições e competências, bem como restringiria os direitos e as garantias individuais, havendo risco de partes vulneráveis sociais e com menor representatividade política perderem a disputa por recursos escassos. O mandado foi indeferido pelo Ministro Luís Roberto Barroso e afastou a possibilidade de inconstitucionalidade devido ao fato de que, com a necessidade de um controle orçamentário por causa da crise econômica atual, a Emenda altera o investimento, como na área da educação, somente por tempo determinado, não sendo, por isso, algo que possa ser considerado contra alguma cláusula pétrea, já que, mesmo de ampla interpretação, não gera prejuízo a nenhum núcleo dos direitos protegidos, considerados pelo magistrado como direitos materialmente fundamentais: os individuais, políticos, sociais e coletivos. O ministro da egrégia corte ainda reforça que barrar tal medida não está ao alcance do STF, já que está fora da possibilidade de controle jurisdicional, ainda mais devido ao fato de a lei versar sobre determinações legais, e não sentenças. Além disso, a Emenda, mesmo em vigor, não poderá alterar as vantagens legais já em vigência antes dela, nem as sentenças já transitadas em julgado.

Segundo, Sarlet, Marinoni e Mitidiero (2013), ao tratarem dos direitos fundamentais sociais, em específico o da educação, dizem que, apesar de o art. 212, que trata do repasse mínimo, alterado pela $P E C n^{\circ} 241 / 2016$, não ser um dispositivo essencial a esse direito, é possível sustentar que uma reforma não poderia supri-lo, pois representa um retrocesso, mesmo de modo indireto, à proteção e à promoção dos direitos fundamentais, considerando-os de uma forma ampla. É algo de notada aceitação que o país tem enfrentado uma crise econômica e política atualmente. Entretanto, mexer com mecanismos que alterem a possibilidade de universalização de direitos fundamentais não pode ser algo permitido. A ideia de obrigatoriedade e de gratuidade do sistema educacional, bem como os diversos dispositivos infraconstitucionais que existem para reforçar a importância da educação, como o Estatuto da Criança e do Adolescente, que firma a necessidade de matrícula e participação da família e prevendo uma responsabilidade civil e penal, mostra de tal forma que os percentuais mínimos garantidos na Constituição, valorizando a esfera da educação, não poderiam ser invocados enquanto objeções à educação fundamental (SARLET; MARINONI; MITIDIERO, 2013).

Percebe-se a necessidade de um investimento adequado para o desenvolvimento da educação, não só como uma forma de desenvolver plenamente os jovens, mas também como uma necessidade para um desenvolvimento social. Tal medida coloca em xeque apenas a manutenção da educação pública, sendo um fator que pode levar à desigualdade no período de vigência de tal proposta e acarretar muito tempo de prejuízo.

\section{CONCLUSÃO}

Tem-se que considerar agora todas essas medidas de uma forma ampla. Se os projetos de lei que versam sobre "Escola Sem Partido", bem como a possível tipificação de crime para garantir a conduta dos profissionais que trabalham na educação, forem aprovadas, tem-se aí uma intervenção política no cerne da educação. É claro que pode haver exagero por parte de alguns profissionais, mas isso deve ser ajustado localmente em cada ambiente de trabalho. Forçar uma lei que retire a liberdade do profissional da educação parece forçar uma ideologia única dentro da escola. Ao contrário do que se tem para uma educação crítica, no qual o aluno deve ter contato com diversas teorias e diversos conhecimentos para, a partir de suas diversas experiências, formar sua própria opinião e seguir como agentes construtor da sociedade, as propostas parecem possibilitar um controle legal da ação do professor por profissionais que não estão relacionados especificamente com a construção da educação.

Segundo Marin (2002), é importante compreender que os tempos políticos são mais curtos que os pedagógicos, sendo necessário haver um consenso para orientar as políticas de forma adequada. A educação enquanto um longo processo não deveria ficar submetida a um possível 
engessamento decorrente de uma legislação, sendo incapaz de se autorregular. A Medida Provisória considerada tem, de fato, aspectos interessantes, como a institucionalização do ensino integral, aumentando a carga horária anual. Entretanto, também possui aspectos complicados, já que, ao tornar obrigatório somente o ensino de Língua Portuguesa e Matemática durante todo o ciclo do Ensino Médio e retira a obrigatoriedade das disciplinas, como Sociologia, Filosofia, Geografia, História, Artes e Educação Física, o que dá um caráter mais técnico à formação, a qual deveria ser para o desenvolvimento pleno da pessoa e para a cidadania, e não só para o trabalho, tornando-se contrário aos princípios norteadores, como a liberdade de aprender e ensinar, divulgando o pensamento, a arte e o saber.

Tudo isso, aliado ainda ao congelamento dos investimentos no setor da educação, torna-se ainda mais complicado, já que tornar a escola em tempo integral exige claramente um aumento do investimento por aluno, pois eleva o número de aulas e o tempo de funcionamento da escola com um mesmo aluno. Com isso, o congelamento dos investimentos, além de possivelmente reduzir o investimento abaixo para o mínimo previsto constitucionalmente, ainda causará uma redução relativa, já que os gastos com a educação tendem a aumentar e, o investimento, a se manter estável.

Há uma controvérsia aos objetivos estabelecidos na construção do processo educacional com a redução das cargas horárias das disciplinas tidas, até então, como necessárias à formação dos cidadãos e com a diminuição do investimento na educação, algo que notadamente é reconhecido como essencial para o desenvolvimento de uma nação. Atrapalhar o andamento da educação e de tudo que tem se construído por formas legais que contrariem o que foi dito é acarretar problemas na formação dos cidadãos, diante as diversas desigualdades, incluindo as educativas; é diminuir ainda mais a possibilidade desse público de atuar de forma consciente e crítica em uma transformação social na busca dos objetivos de construir uma sociedade livre, justa e solidária e garantir o desenvolvimento nacional.

O fato de o impacto direto da educação sobre importantes variáveis não-econômicas ser tão ou mais importante que o seu impacto sobre as variáveis econômicas revela que investimentos em educação têm importantes externalidades sociais que tornam o subinvestimento em educação ainda mais penoso para o desenvolvimento humano de uma sociedade (BARROS; MENDONÇA, 1997).

Os 25 anos para o atraso de desenvolvimento previstos ainda nem terminaram e já se quer reduzir os gastos com a educação, pois são contrariadas as metas estabelecidas do Plano Nacional de Educação, com vigência de 2014 a 2024, em que seriam ampliadas as verbas da educação para $10 \%$ do PIB nacional. Contudo, tem-se o delineamento de uma situação extremamente complicada para o cenário educacional brasileiro, que parece que começa a caminhar para trás. Deve-se ficar atento aos mecanismos criados pelo governo, pois, como é possível perceber, é só pela educação que a sociedade se transforma. Não havendo uma educação concernente e com investimentos adequados, tem-se uma estagnação social, cultural e econômica que pode mergulhar o país em décadas de atraso.

Por tudo isso exposto neste trabalho, pode-se considerar o conjunto desses instrumentos legais como formas de retrocesso no processo educacional existentes até então.

\section{REFERÊNCIAS}

ABDALLA, S.; DRECHSEL, D. Proposta de reforma do ensino médio divide especialistas; saiba o que muda. Gazetta do Povo, Curitiba, PR, 22 set. 2016. Educação. Disponível em: <http://www. gazetadopovo.com.br/educacao/proposta-de-reformado-ensino-medio-divide-especialistas-saiba-o-quemuda-3sb7aagi3vo1mtks21zdwlr4w $>$. Acesso em: 1 nov 2016.

BARROS, R. P.; MENDONÇA, R. Investimentos em educação e desenvolvimento econômico. Rio de Janeiro: Instituto de Pesquisa Econômica Aplicada, 1997. Disponível em: <http://repositorio.ipea.gov. br/bitstream/11058/2308/1/td_0525.pdf $>$. Acesso em: 1 nov. 2016.

BRANDÃO, C. R. O que é educação? São Paulo: Brasiliense, 2007.

BRASIL. Casa Civil. Subchefia para Assuntos Jurídicos. Lei de 15 de outubro de 1827. Coleção de Leis do Império do Brasil, Rio de Janeiro, RJ, 1827.

BRASIL. Senado Federal. Constituição da República Federativa do Brasil de 1988. Diário Oficial [da] 
República Federativa do Brasil, Brasília, DF, 5 out. 1988.

BRASIL. Ministério da Educação. Lei de Diretrizes e Bases da Educação Nacional. Lei no 9394, de 20 de dezembro de 1996. Diário Oficial [da] República Federativa do Brasil, Brasília, DF, 23 dez. 1996.

BRASIL. Plano Nacional de Educação. Lei ${ }^{\circ}$ 13.005, de 25 de junho de 2014. Estabelece o Plano Nacional da Educação para o decânio 2014-2024. Diário Oficial [da] República Federativa do Brasil, Brasília, DF, 26 jun. 2014a. Seção 1, Edição Extra.

BRASIL. Câmara dos Deputados. Plano Nacional de Educação (PNE) 2014-2024. Brasília: Edições Câmara, 2014b.

BRASIL. Ministério da Educação-MEC. Secretaria de Articulação com os Sistemas de Ensino - SASE. Planejando a próxima década: conhecendo as 20 metas do Plano Nacional de Educação. Brasília, 2014c.

BRASIL. Câmara dos Deputados. Projeto de Lei no 1411 de 2015. Brasília, 2015a. Disponível em: $<$ http://www.camara.gov.br/sileg/integras/1335560. pdf $>$. Acesso em: 1 nov. 2016.

BRASIL. Câmara dos Deputados. Projeto de Lei no 867 de 2015. Brasília, 2015b. Disponível em: $<$ http://www.camara.gov.br/sileg/integras/1317168. pdf $>$. Acesso em: 1 nov. 2016.

BRASIL. Presidência da República. Casa Civil. Subchefia para Assuntos Jurídicos. Medida Provisória $\mathrm{n}^{\circ}$ 746, de 22 de setembro de 2016. Diário Oficial [da] República Federativa do Brasil, Brasília, DF, 23 set. 2016a.

BRASIL. Ministério Público Federal. Procuradoria Federal dos Direitos do Cidadão. Nota técnica 01/2016. Brasília, 2016b. Disponível em: <http:// pfdc.pgr.mpf.mp.br/temas-de-atuacao/educacao/ saiba-mais/proposicoes-legislativas/nota-tecnica01-2016-pfdc-mpf>. Acesso em: 1 nov. 2016.

BRASIL. Proposta de Emenda Constitucional 241 de 2016. Brasília, 2016c. Disponível em: <http://www. camara.gov.br/proposicoesWeb/prop_mostrarinte gra?codteor $=1468431 \&$ filename $=$ PEC241/2016 . . Acesso em: 1 nov. 2016.

BRASIL. Senado Federal. Projeto de Lei do Senado ${ }^{\circ}$ 193, de 2016. Brasília, 2016d. Disponível em: <http://
www.senado.leg.br/atividade/rotinas/materia/getPDF. asp?t=192259\&tp=1>. Acesso em: 1 nov. 2016.

FREIRE, P. Pedagogia do oprimido. 11. ed. São Paulo: Paz e Terra, 1970.

FREIRE, P. Educação e mudança. 12. ed. São Paulo: Paz e Terra, 1979.

MARIN, J. P. A. Gestão e sustentabilidade das reformas educativas. In: ORGANIZAÇÃO DAS NAÇÕES UNIDAS PARA A EDUCAÇÃO, A CIÊNCIA E A CULTURA - UNESCO. Equidade e financiamento da educação na América Latina. Brasília: UNESCO, 2002.

NAGIB, M. Liberdade de ensinar não se confunde com a liberdade de expressão. Conjur, [S.1.], 24 jun. 2016. Disponível em: <http://www.conjur.com. br/2016-jun-24/miguel-nagib-liberdade-ensinarnao-confunde-expressao>. Acesso em: 1 nov. 2016.

OTTO, H. S. Entenda o que é o movimento "Escola Sem Partido" e o Projeto de Lei n.867/2015. Jusbrasil, Salvador, jun. 2016. Disponível em: <https://hyagootto. jusbrasil.com.br/artigos/361100592/entenda-o-quee-o-movimento-escola-sem-partido-e-o-projeto-delei-n-867-2015>. Acesso em: 1 nov. 2016.

PESSOA, E. A. A Constituição Federal e os direitos sociais básicos ao cidadão brasileiro. Âmbito Jurídico, v. 14, n. 89, 2011.

SAMPAIO, C. "Projeto escola sem partido é uma ode ao atraso", diz professor. Brasil de Fato, Brasília, 18 jul. 2016. Disponível em: $<$ https://www.brasildefato. com.br/2016/07/18/projeto-escola-sem-partido-euma-ode-ao-atraso-diz-professor/>. Acesso em: 1 nov. 2016.

SARLET, I. W; MARINONI, L. G; MITIDIERO, D. Curso de Direito Constitucional. 2. ed. São Paulo: Revista dos Tribunais, 2013.

TOKARNIA, M. Professores e sindicatos criticam MP do Ensino Médio em audiência pública. EBCAgência Brasil, Brasília, 16 maio 2016. Disponível em: <http:/ agenciabrasil.ebc.com.br/educacao/noticia/2016-10/ mp-do-ensino-medio-sofre-resistencia-na-primeiraaudiencia-publica-na>. Acesso em: 1 nov. 2016.

VIEIRA, S. L. A educação nas constituições brasileiras: texto e contexto. Revista Brasileira de Estudos Pedagogicos, v. 88, n. 219, p. 291-309, 2007. 